\title{
Transanal total mesorectal excision (taTME) for rectal cancer: a systematic review and meta-analysis of oncological and perioperative outcomes compared with laparoscopic total mesorectal excision
}

\author{
Bin $\mathrm{Ma}^{\dagger}$, Peng Gao ${ }^{\dagger}$, Yongxi Song, Cong Zhang, Changwang Zhang, Longyi Wang, Hongpeng Liu \\ and Zhenning Wang*
}

\begin{abstract}
Background: Transanal total mesorectal excision (taTME) is an emerging surgical technique for rectal cancer. However, the oncological and perioperative outcomes are controversial when compared with conventional laparoscopic total mesorectal excision (laTME).

Methods: A systematic review and meta-analysis based on Preferred Reporting Items for Systematic Reviews and Meta-analyses (PRISMA) guidelines was conducted in PubMed, Embase and Cochrane database. All original studies published in English that compared taTME with laTME were included for critical appraisal and meta-analysis. Data synthesis and statistical analysis were carried out using RevMan 5.3 software.
\end{abstract}

Results: A total of seven studies including 573 patients (taTME group = 270; laTME group =303) were included in our meta-analysis. Concerning the oncological outcomes, no differences were observed in harvested lymph nodes, distal resection margin (DRM) and positive DRM between the two groups. However, the taTME group showed a higher rate of achievement of complete grading of mesorectal quality $(\mathrm{OR}=1.75,95 \% \mathrm{Cl}=1.02-3.01, P=0.04)$, a longer circumferential resection margin (CRM) and less involvement of positive CRM (CRM: WMD $=0.96,95 \% \mathrm{Cl}=0$. $60-1.31, P<0.01$; positive $C R M: O R=0.39,95 \% C l=0.17-0.86, P=0.02$ ). Concerning the perioperative outcomes, the results for hospital stay, intraoperative complications and readmission were comparable between the two groups. However, the taTME group showed shorter operation times (WMD $=-23.45,95 \% \mathrm{Cl}=-37.43$ to $-9.46, P<0.01)$, a lower rate of conversion $(\mathrm{OR}=0.29,95 \% \mathrm{Cl}=0.11-0.81, P=0.02)$ and a higher rate of mobilization of the splenic flexure $(\mathrm{OR}=2.34,95 \% \mathrm{Cl}=0.99-5.54, P=0.05)$. Although the incidence of anastomotic leakage, ileus and urinary morbidity showed no difference between the groups, a significantly lower rate of overall postoperative complications $(\mathrm{OR}=0.65,95 \% \mathrm{Cl}=0.45-0.95, P=0.03)$ was observed in the taTME group.

Conclusions: In comparison with laTME, taTME seems to achieve comparable technical success with acceptable oncologic and perioperative outcomes. However, multicenter randomized controlled trials are required to further evaluate the efficacy and safety of taTME.

Keywords: Transanl TME, Laparoscopic TME, Rectal cancer, Short-term outcomes

\footnotetext{
* Correspondence: josieon826@sina.cn

${ }^{\dagger}$ Equal contributors

Department of Surgical Oncology and General Surgery, the First Hospital of

China Medical University, Shenyang 110001, People's Republic of China
} 


\section{Background}

Rectal cancer ranks as one of the most common types of carcinoma throughout the world [1]. Over recent decades, total mesorectal excision (TME) performed by an open approach has become the standard technique for the surgical treatment of rectal cancer [2]. Over time, to achieve a minimally invasive surgical treatment, TME has shifted from the open approach to a laparoscopic technique. Recently published randomized clinical trials (RCTs), such as COLOR II, COREAN and CLASICC, have shown better results for laparoscopic total mesorectal excision (laTME), in terms of short-term and long-term outcomes, when compared with open TME [3-6]. However, the utility of laTME is limited in patients with low rectal cancer, who require surgeons with experience in ultra-low sphincter-saving laparoscopic surgery, which has a high risk of leaving a positive circumferential resection margin (CRM). In addition, narrow pelvic anatomy, male sex and high body mass index (BMI) are also unfavorable patient characteristics for a laparoscopic approach [7]. Furthermore, because of the limited view of the distal margin of the tumor, conversion rates to open procedures remain unsatisfactory $[8,9]$. The pressing need to overcome these challenges has motivated surgeons to develop alternative techniques for treatment of rectal cancer, especially for patients with mid- and low-rectal lesions.

Based on the aforementioned considerations, the concept of a "down-to-up" procedure and transanal TME (taTME) has been proposed to give a new option in cases where laTME is difficult. In fact, taTME is not a completely novel concept and it has benefited from previous experience of transabdominal-transanal (TATA) operations, transanal endoscopic microsurgery (TEM), transanal minimally invasive surgery (TAMIS) and natural orifice transluminal endoscopic surgery (NOTES) [10-12]. Since the first taTME resection assisted by laparoscopy was reported in 2010 [13], taTME performed on patients with rectal cancer has showed promising results with regard to pathological quality, and short- and midterm outcomes [14-16]. Although taTME may improve the distal mesorectal dissection, which is the most technically challenging part of a transabdominal TME, whether the oncological and perioperative outcomes of taTME are better than those of laTME remains controversial. Hence, a quantitative analysis was necessary to provide direct evidence of the benefits of taTME.

Therefore, this meta-analysis was conducted to compare the oncological and perioperative outcomes of taTME and laTME for patients with mid- and low-rectal cancer.

\section{Methods}

\section{Search strategy}

This systematic review and meta-analysis were conducted in accordance with Preferred Reporting Items for
Systematic Reviews and Meta-analyses (PRISMA) guidelines (http://www.prisma-statement.org/) [17]. A comprehensive search of published studies was performed in PubMed, Embase and the Cochrane Database (from January 2010 to November 2015). The MeSH and main keywords were as follows: "transanal", "transanal total mesorectal excision" or "taTME", "transanal minimally invasive surgery" or "TAMIS", "transanal endoscopic microsurgery" or "TEM", "natural orifice transluminal endoscopic surgery" or "NOTES", "perineal approach", "rectal cancer" and "proctectomy". Based on these MesH and main keywords, we formulated the search strategy (for PubMed) as following: (transanal OR transanal minimally invasive surgery OR TAMIS OR transanal endoscopic microsurgery OR TEM OR transanal specimen extraction OR natural orifice specimen extraction OR NOSE OR natural orifice transluminal endoscopic surgery OR NOTES OR peritoneal) AND (total mesorectal excision OR TME OR proctectomy) AND rectal. All the relevant studies which described a comparison between taTME and laTME were checked carefully (including the reference lists of relevant studies). All studies were restricted to the English language.

\section{Inclusion and exclusion criteria}

According to the PICOS criteria (population, intervention, comparison, outcomes and study design), studies were selected in our present meta-analysis according to the following eligibility criteria: (1) population: patients were definitely diagnosed with rectal cancer; (2) intervention: surgical treatment for rectal cancer (taTME/ laTME); (3) comparison: taTME versus laTME; (4) outcomes: oncological and perioperative outcomes compared between two groups; (5) study design: randomized controlled trials, cohort trials or matched case-control trials with sample size greater than 20. The exclusion criteria were: (1) no laTME group as a control; (2) absence of the outcomes of interest; (3) duplicate publication or provision of insufficient data. All the studies included were checked carefully once again to avoid the inclusion of studies which were based on the same database or patient population as another included report.

\section{Data extraction and assessment of the risk of bias}

Two reviewers (B Ma and P Gao) reviewed and assessed each of the included studies. In addition, data extraction was performed independently, and the following information was collected: (1) study characteristics: first author, year of publication, country, study type (RCT/cohort trial/ matched case-control trial) and number of patients enrolled; (2) patient baseline: sex, age, tumor site (mid/low), tumor location (distance above the anal verge), body mass index, neoadjuvant treatment, American Society of Anesthesiologists (ASA), pT stage and $\mathrm{pN}$ stage; (3) study 
design: surgical type of taTME (partial/total), oncological outcomes (quality of mesorectum, harvested lymph nodes, CRM, positive CRM, distal resection margin (DRM), positive DRM and perioperative outcomes (operation time, conversion, mobilization of splenic flexure, hospital stay, intraoperative complications, postoperative complications and readmission). The Newcastle-Ottawa Scale (NOS) criterion was used to evaluate the quality of the studies included [18]. All disagreements were resolved by discussion between the two reviewers (B Ma and P Gao).

\section{Statistical analysis}

In this meta-analysis, continuous variables representing the oncological and perioperative outcomes were analyzed by the weighted mean difference (WMD). If the study did not provide values for the mean and standard deviation (SD), we used the method of Hozo et al. to calculate the mean and SD for our overall analysis [19]. We used odds ratios (ORs) to evaluate the dichotomous variables for the oncological and perioperative outcomes. In addition, the $\mathrm{Q}$ test and $\mathrm{I}^{2}$ statistic were used to evaluate heterogeneity among studies. A Cochrane Q statistical $P$ value $<0.10$ and/or $\mathrm{I}^{2}>50 \%$ was taken to indicate significant heterogeneity, and in this case a randomeffects model was used for the pooled analysis [20, 21]. Otherwise, a fixed-effects model was employed. All statistical values were computed with $95 \%$ confidence intervals (CI), and the two-tailed $P$ value threshold for statistical significance was set at 0.05 . Furthermore, based on the surgical type of taTME, we conducted a subgroup analysis to explore further the advantages of total taTME using a laparoscopic approach. Finally, publication bias was tested using funnel plots. All the statistical analyses were performed using software from the Cochrane Collaboration (RevMan v5.3; Nordic Cochrane Centre).

\section{Results}

\section{Selected studies}

The search strategy initially identified 923 studies (Pubmed $=275$; other databases $=648$ ). After exclusion of duplicates and irrelevant studies, 11 potentially relevant studies were obtained for further assessment. Among these studies, three studies were conference abstracts from which we could not extract sufficient information for our final analysis [22-24]. In addition, one report described a protocol for a multicenter RCT comparing transanal TME and laTME for midand low-rectal cancer [25]. Finally, seven studies including 573 patients were included our meta-analysis (taTME group = 270; laTME group = 303) [26-32]. A flow chart of the search strategies, which includes the reasons for exclusion of studies, is illustrated in Fig. 1. The seven studies were from France, the Netherlands, Taiwan, Spain and Denmark. The study characteristics, patient baseline data and methodological quality assessment scores of the studies included are summarized in Table 1.

\section{Oncological outcomes}

The quality of the mesorectum was scored using three grades (complete, nearly complete and incomplete), as defined by Quirke [33]. On the basis of this standardized method, five of the studies included reported the macroscopic quality of the mesorectum [26, 28, 29, 31, 32]. After pooled analysis, the complete grade for the quality of the mesorectum was significantly higher for taTME than for laTME $(\mathrm{OR}=1.75,95 \% \mathrm{CI}=1.02-3.01, P=0.04$; Fig. 2a). All the studies included provided information on harvested lymph nodes. The pooled analysis of the seven studies showed that harvested lymph nodes were equivalent between the two groups (WMD $=0.00,95 \%$ $\mathrm{CI}=-1.24-1.25, P=1.00$; Fig. 2b).

With regard to the surgical resection margin, all the studies provided sufficient data on CRM and DRM. Among them, three studies reported patients who achieved complete remission after neoadjuvant treatment [28-30] and two studies evaluated the CRM and DRM only in patients without complete response after neoadjuvant treatment $[29,30]$. We excluded the patients with complete remission in these two studies from our overall analysis of the outcomes of CRM and DRM. In the pooled data, the taTME group showed a significantly greater CRM than the laTME group (WMD $=0.96,95 \% \mathrm{CI}=$ 0.60-1.31, $P<0.01$; Fig. 2c), but a comparable DRM was observed between the two groups (WMD $=2.71$, 95\% $\mathrm{CI}=-1.97-7.39, P=0.26$; Fig. $2 \mathrm{~d})$. Among the studies, six provided data on positive CRM [26-29, 31, 32] and three on positive DRM [27, 29, 32]. Meta-analysis indicated that a significantly lower number of patients in the taTME group had a positive CRM $(\mathrm{OR}=0.39$, 95\% CI $=0.17-0.86, P=0.02$; Fig. $2 \mathrm{e}$ ), but there was comparable DRM involvement between the two groups (OR = 1.65, 95\% CI =0.17-16.40, $P=0.67$; Fig. 2f).

Except for the outcomes of DRM and positive DRM, all the other oncological outcomes showed no significant heterogeneity between the groups. Detailed information on the oncological outcomes of included studies is summarized in Table 2 .

\section{Perioperative outcomes}

Given that Velthuis et al. [31] only provided results on the pathological characteristics, a meta-analysis was conducted using the remaining six studies to compare the operative and perioperative outcomes between the two groups. In terms of operative outcomes, data on operation time, conversion rate and hospital stay were available for these six studies [26-30, 32]. After pooled analysis, we found that the taTME group showed a significantly shorter operation time (WMD $=-23.45$, 


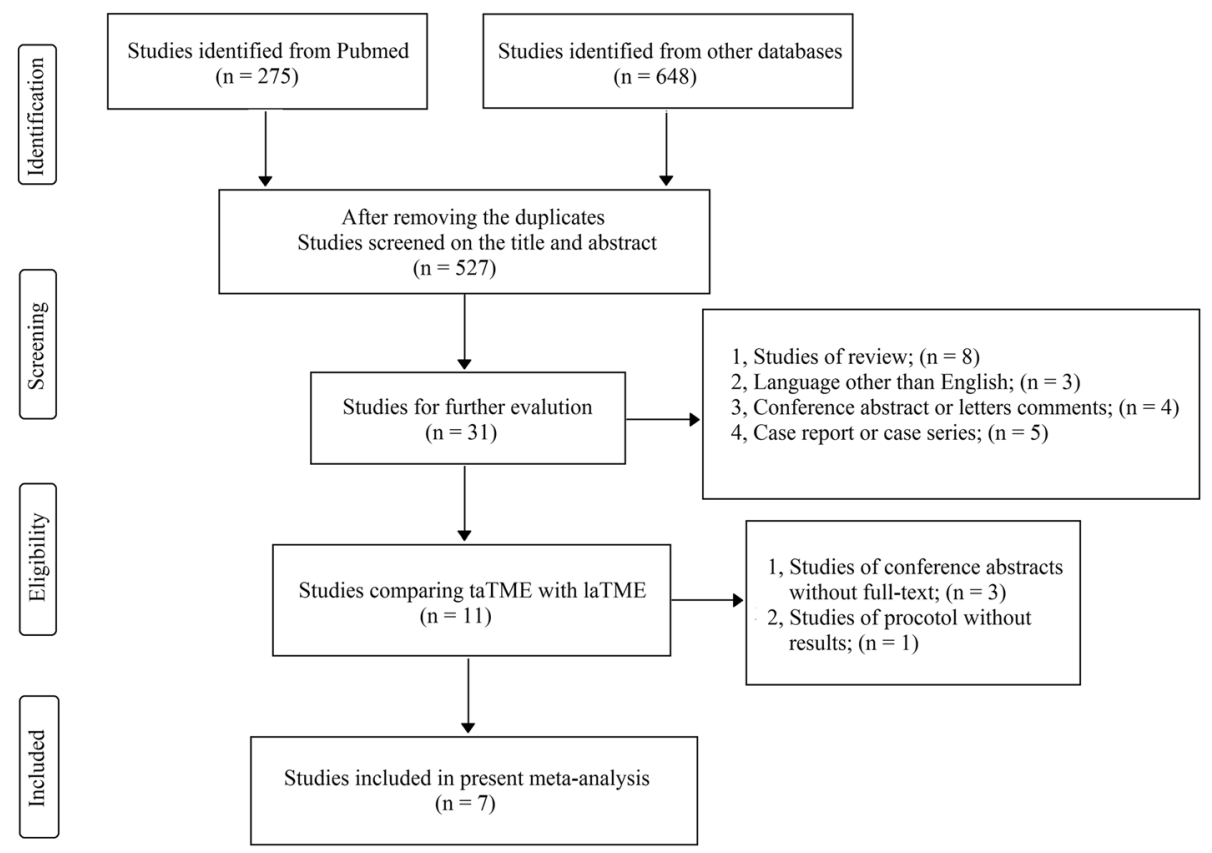

Fig. 1 Flow chart showing the selection process for the included studies

95\% CI $=-37.43$ to $-9.46, P<0.01$; Fig. 3a), a lower conversion rate $(\mathrm{OR}=0.29,95 \% \mathrm{CI}=0.11-0.81, P=0.02$; Fig. $3 \mathrm{~b}$ ) and a comparable hospital stay (WMD $=-1.18$, 95\% CI $=-2.94-0.59, P=0.19$; Fig. 3c). Three studies provided data on mobilization of the splenic flexure in the two groups $[26,28,30]$ and more mobilization of the splenic flexure was achieved in the taTME group $(\mathrm{OR}=$ 2.34, 95\% CI $=0.99-5.54, P=0.05$; Fig. $3 d$ ). In addition, a pooled analysis of intraoperative complications, based on four studies, was conducted [26, 28-30] and there was no difference between the groups for this outcome ( $\mathrm{OR}=0.94,95 \% \mathrm{CI}=0.30-3.01, P=0.92$; Fig. 3e). Two studies also indicated that the taTME group showed significantly less blood loss $[26,30]$ and we did not conduct a pooled analysis because the low number of studies caused considerable heterogeneity.

Regarding the short-term outcomes, all six remaining studies provided information about postoperative complications. In the pooled data, the taTME group showed a significantly lower rate of postoperative complications than the laTME group $(\mathrm{OR}=0.65,95 \% \mathrm{CI}=0.45-0.95$, $P=0.03$; Fig. 4a). Of note, the occurrence of anastomotic leakage, ileus and urinary morbidity was comparable between the two groups (anastomotic leakage: OR = $0.78,95 \% \mathrm{CI}=0.44-1.40, P=0.41$; ileus: $\mathrm{OR}=1.00,95 \%$ $\mathrm{CI}=0.45-2.19, P=1.00$; urinary morbidity: $\mathrm{OR}=0.48$, $95 \% \mathrm{CI}=0.22-1.03, P=0.06$; Fig. $4 \mathrm{~b}-\mathrm{d})$. In addition, four studies reported the readmission rate [26, 28-30]. A pooled analysis showed a tendency that fewer patients after taTME would require readmission, although this was not statistically significant $(\mathrm{OR}=0.52,95 \% \mathrm{CI}=$ 0.24-1.10, $P=0.09$; Fig. 4e).

Except for operative time, hospital stay and molization of splenic flexure, no significant heterogeneity was observed between the groups for other perioperative outcomes. Detailed information on the perioperative outcomes of included stuedies is also summarized in Table 2.

\section{Subgroup analyses}

The term taTME includes two different concepts (partial and total taTME) [34]. Among the studies included in the meta-analysis, two reported the use of conventional retractors to perform a partial taTME [27, 32] the other five studies used a standard transanal access platform to perform a total taTME [26, 28-31]. Hence, to eliminate the heterogeneity introduced by differences in surgical technique, we conducted a subgroup analysis of the oncological and perioperative outcomes, based on total taTME, to further verify our pooled results. Our subgroup analysis showed that the benefits of total taTME were obvious, which was consistent with our overall analysis (Table 3).

\section{Discussion}

Laparoscopic procedures are generally thought to have better outcomes than open procedures. However, recent two RCTs (AlaCaRT and ACOSOG Z6051) both confirmed that laparoscopic resection failed to meet the criterion for noninferiority for pathologic outcomes when compared with open section for rectal cancer patients [35, 36]. An 
Table 1 Baseline characteristics of the included studies

\begin{tabular}{|c|c|c|c|c|c|c|c|c|c|c|c|c|c|c|}
\hline \multirow[t]{2}{*}{$\begin{array}{l}\text { Studies } \\
\text { (NOS score) }\end{array}$} & \multirow[t]{2}{*}{ Year } & \multirow[t]{2}{*}{ Country } & \multirow[t]{2}{*}{ Study design } & \multirow{2}{*}{$\begin{array}{l}\text { Gender } \\
\text { Male/Female } \\
\text { taTME laTME }\end{array}$} & \multicolumn{2}{|c|}{$\begin{array}{l}\text { BMI Mean } \pm \text { SD/median } \\
\text { (range) }\end{array}$} & \multicolumn{2}{|c|}{$\begin{array}{l}\text { Age Mean } \pm \text { SD/median } \\
\text { (range) }\end{array}$} & \multicolumn{2}{|c|}{ ASA I + II/III+IV } & \multirow[t]{2}{*}{ Tumor location } & \multicolumn{2}{|c|}{$\begin{array}{l}\text { Neoadjuvant treatment } \\
\text { (Yes/No) }\end{array}$} & \multirow[t]{2}{*}{ taTME type } \\
\hline & & & & & taTME & laTME & taTME & laTME & taTME & laTME & & taTME & laTME & \\
\hline $\begin{array}{l}\text { Velthuis [31] } \\
\text { (3) } 2014\end{array}$ & & Netherland & MCC & $18 / 7$ 18/7 & $25(20-36)$ & $28(21-34)$ & $\mathrm{NR}$ & NR & NR & NR & low/mid & $25 / 0$ & $25 / 0$ & Total \\
\hline Kanso [27] (6) & 2015 & France & MCC & $36 / 1526 / 8$ & $24 \pm 4$ & $24 \pm 4$ & $59 \pm 11$ & $59 \pm 11$ & $47 / 4$ & $31 / 3$ & low & $43 / 41^{a}$ & $28 / 27^{\mathrm{a}}$ & Partial \\
\hline Hevia [28] (4) & 2014 & Spain & MCC & $24 / 1322 / 15$ & $23.7 \pm 3.6$ & $25.1 \pm 4.0$ & $64.5 \pm 11.8$ & $69.5 \pm 10.5$ & $30 / 7$ & $25 / 12$ & low/mid & $28 / 9$ & $23 / 14$ & Total \\
\hline Chen [30] (4) & 2015 & Taiwan & MCC & $38 / 12$ 76/24 & $24.2 \pm 3.7$ & $24.6 \pm 3.1$ & $57.3 \pm 11.9$ & $58.3 \pm 11.3$ & $33 / 17$ & $69 / 31$ & low/mid & $50 / 0$ & $100 / 0$ & Total \\
\hline $\begin{array}{l}\text { Denost [32] } \\
\text { (6) } 2014\end{array}$ & & France & RCT & $37 / 13$ 32/18 & $25(17-33)$ & $26(18-38)$ & 64 (39-82) & $63(31-90)$ & $49 / 1$ & $49 / 1$ & low & $40 / 10$ & $44 / 6$ & Partial \\
\hline $\begin{array}{l}\text { Perdawood } \\
\text { [26] (4) } 2015\end{array}$ & & Denmark & MCC & 19/6 19/6 & $28(18-46)$ & $26(19-38)$ & 70 (54-76) & 70 (49-84) & $19 / 6$ & $22 / 3$ & low/mid & $7 / 18$ & $4 / 21$ & Total \\
\hline $\begin{array}{l}\text { Angelis [29] } \\
\text { (4) } 2015\end{array}$ & & France & MCC & $21 / 1121 / 11$ & $25.2 \pm 3.5$ & $24.5 \pm 3.2$ & $64.9 \pm 10.0$ & $67.2 \pm 9.6$ & $31 / 1$ & $31 / 1$ & low/mid & $27 / 5$ & $23 / 9$ & Total \\
\hline
\end{tabular}

taTME transanal total mesorectal excision, laTME laparoscopic total mesorectal excision, BMI body mass index, ASA American Society of Anesthesiologists, $M C C$ matched case control, RCT randomized controlled trial, aln taTME group, 43 patients received neoadjuvant radiotherapy and 41 patients received neoadjuvant chemotherapy. In laTME group, 28 patients received neoadjcpuvant radiotherapy and 27 patients received neoadjuvant chemotherapy 


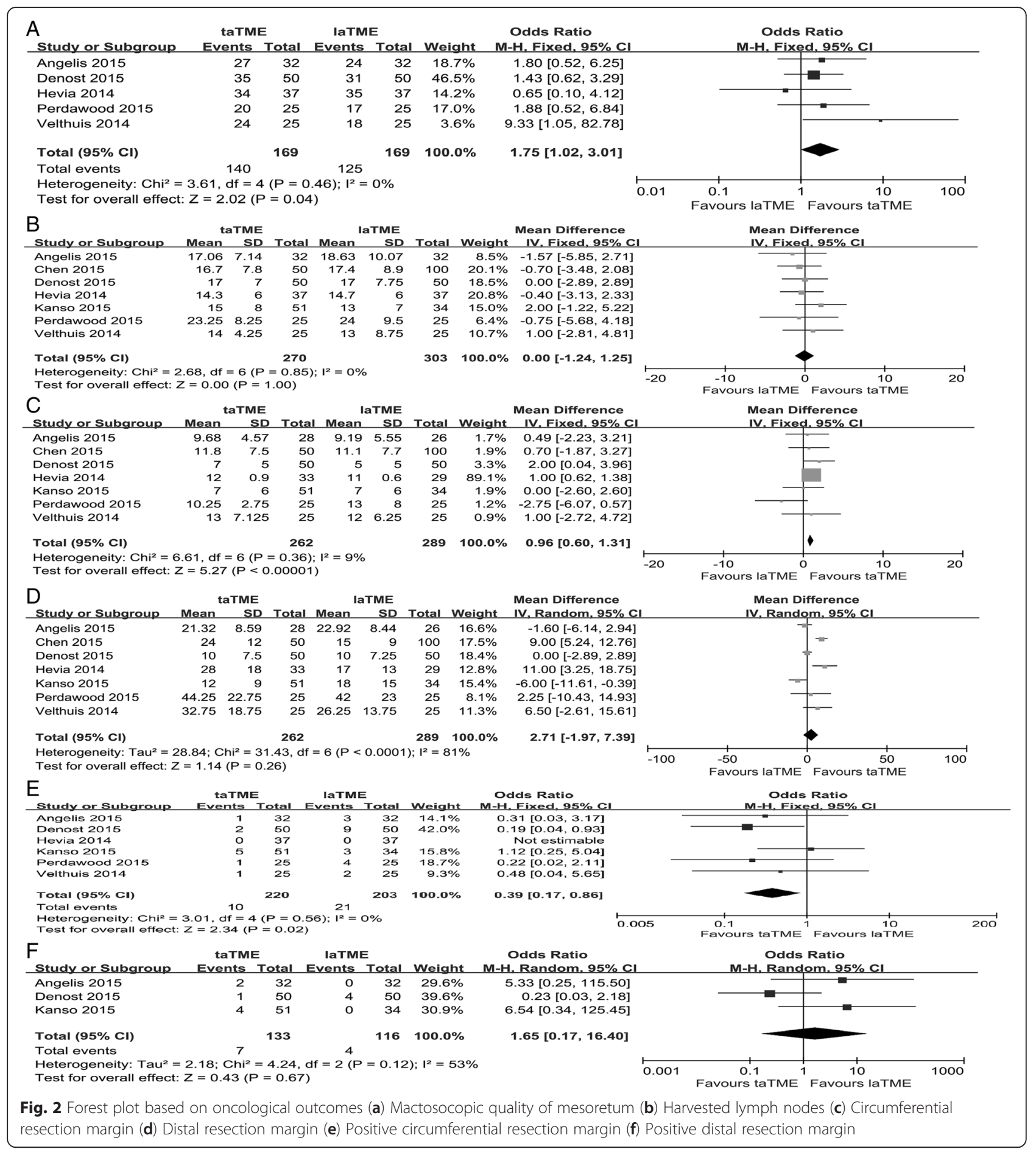

explanation for this finding is that proctectomy can be very difficult to work in the deep pelvis with in-line rigid instruments from angles that require complicated maneuvers to reach the extremes of the pelvis. Hence, both AlaCaRT and ACOSOG Z6501 indicated that modification of instruments or a different platform such as robotics or taTME will improve efficacy of minimally invasive techniques. Over the last decade, transanal approaches have been extensively used to overcome the inherent shortcomings of laTME [37-39]. Among these emerging transanal techniques, taTME is a new minimally invasive procedure with essential aim of improving oncological treatment quality and avoiding pelvic nerve injury in patients with mid- or lowrectal cancer. Given the encouraging outcomes of systematic investigation of taTME for patients with rectal cancer $[40,41]$ taTME may be optimized as a surgical 
Table 2 Detailed information of oncological and perioperative outcomes of included studies

\begin{tabular}{|c|c|c|c|c|c|c|c|}
\hline Studies & Velthuis [31] & Kanso [27] & Hevia [28] & Chen [30] & Denost [32] & Perdawood [26] & Angelis [29] \\
\hline Mactoscopic quality of mesorectum & * & & $*$ & & * & * & * \\
\hline Harvested lymph nodes & * & * & * & * & * & * & * \\
\hline Circumferential resection margin & * & * & * & * & * & * & * \\
\hline Positive circumferential resection margin & * & * & * & & * & * & * \\
\hline Distal resection margin & * & * & * & * & * & * & * \\
\hline Positive distal resection margin & & * & & & * & & * \\
\hline Length of resected specimen & * & & & & & & * \\
\hline Complete remission after neoadjuvant & & & * & * & & & * \\
\hline Operative time & & * & * & * & * & * & * \\
\hline Conversion & & * & * & * & * & * & * \\
\hline Hospital stay & & * & * & * & * & * & * \\
\hline Intraoperative complications & & & * & $*$ & & * & * \\
\hline Postoperative complications & & * & * & * & * & * & * \\
\hline Anastomotic leakage & & * & * & * & * & * & * \\
\hline lleus & & & * & * & * & * & * \\
\hline Acute urinary retention & & & * & * & * & * & * \\
\hline Blood loss & & & & $*$ & & * & \\
\hline Mobilization of splenic flexure & & & * & * & & * & \\
\hline Readmission & & & * & * & & * & * \\
\hline Mortality & & * & & & * & & * \\
\hline Type of anastomosis & & * & * & $*$ & & * & \\
\hline Disease-free survival & & * & & & & & \\
\hline Starting diet period & & & $*$ & & & & \\
\hline Days to Foley removal & & & & $*$ & & & \\
\hline Diverting Ostomy & & & * & $*$ & & & \\
\hline
\end{tabular}

approach for rectal cancer. In comparison with conventional laTME, taTME defines the distal resection margin more precisely, with better visualization of the distal rectum, and allows the surgeon to perform the deep pelvic dissection without the need for difficult retraction (even in the deep, narrow male pelvis or in obese patients) [42]. Heald has already stressed the importance of taTME as a new solution to some old problems [43]. However, the benefits of taTME compared with laTME must be confirmed before carrying out multicenter RCTs and unifying taTME procedures. Hence, we conducted this quantitative meta-analysis to investigate whether taTME can show significant benefits with regard to oncological and perioperative outcomes, when compared with laTME.

Based on the results of our meta-analysis for oncological outcomes, we found that patients in the taTME group had a significantly higher rate of complete specimens, longer CRM and less positive CRM involvement. In addition, in terms of perioperative outcomes, the taTME group had significantly shorter operation times and a lower conversion rate. Of note, a significantly lower rate of postoperative complications was observed in the taTME group in comparison with the laTME group. Our findings have provided direct evidence that taTME shows benefits with regard to short-term outcomes for patients with rectal cancer.

Our overall and subgroup analyses both indicated the significant advantages of taTME in achieving complete grading of mesorectal quality. Complete or nearly complete mesorectal fascia is a recognized and universally accepted positive prognostic factor, whereas an incomplete fascia is associated with unfavorable oncological outcomes [44]. Based on the studies included, the percentage of patients with complete mesorectum was $83.4 \%$ in the taTME group and $73.4 \%$ in the laTME group. In addition, achievement of complete plus nearly complete mesorectum was also greater in the taTME group (95.3\% versus $88.2 \%)$. Hence, for patients with mid- or low-rectal cancer, taTME may achieve a complete or nearly complete resection of the mesorectum relative easily, compared with laTME. However, whether a higher quality of mesorectal resection will convert into longer survival remains unknown. 


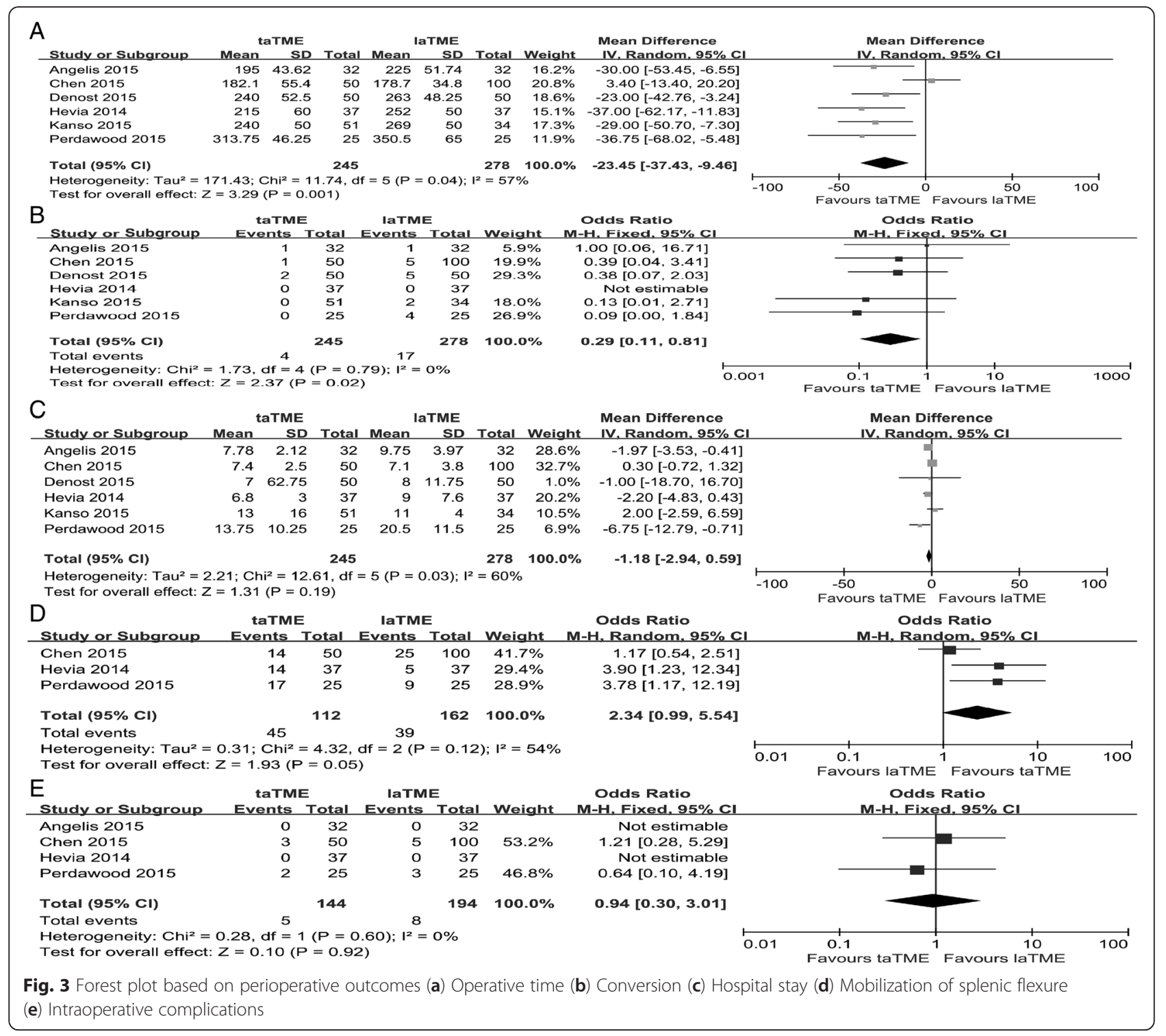

The CRM and positive CRM are important indicators of the outcome for patients undergoing TME for rectal cancer [45, 46]. Our results confirmed a significant advantage of taTME in CRM and less positive CRM involvement. However, for the DRM and positive DRM, our results did not reach statistical significance. On one hand, considerable heterogeneity was observed for these two outcomes, which may have been caused by differences in tumor location. In fact, two studies enrolled patients with only low rectal cancer [27, 32], the other five studies enrolled patients with mid- or low-rectal cancer [26, 28-31]. On the other hand, a significant difference in the distance of the tumor from the anal verge was observed in Chen's study $(P=0.022)$ [30]. Although we could not eliminate the heterogeneity of DRM and positive DRM in our present study, on the basis of the rationale of the dissection in taTME, the potential advantages in these two outcomes justify further study in a large RCT.

With regard to the operative outcomes, taTME and laTME showed comparable results for hospital stay and readmission rate. However, a significantly shorter operation time and lower conversion rate were observed for taTME. One explanation is that taTME can be performed by two teams simultaneously, which obviously decreased the operation time in the pooled analysis $[28,30]$. However, it is noteworthy that six of the included studies showed a shorter operation time for the taTME group, irrespective of whether one or two teams were working. The "down-to-up" procedure indeed overcomes the technical limitations of laparoscopy and helps surgeons perform the surgical procedures efficiently. In addition, we assessed the reasons for conversion of the approach. In the taTME group, only one patient underwent conversion 


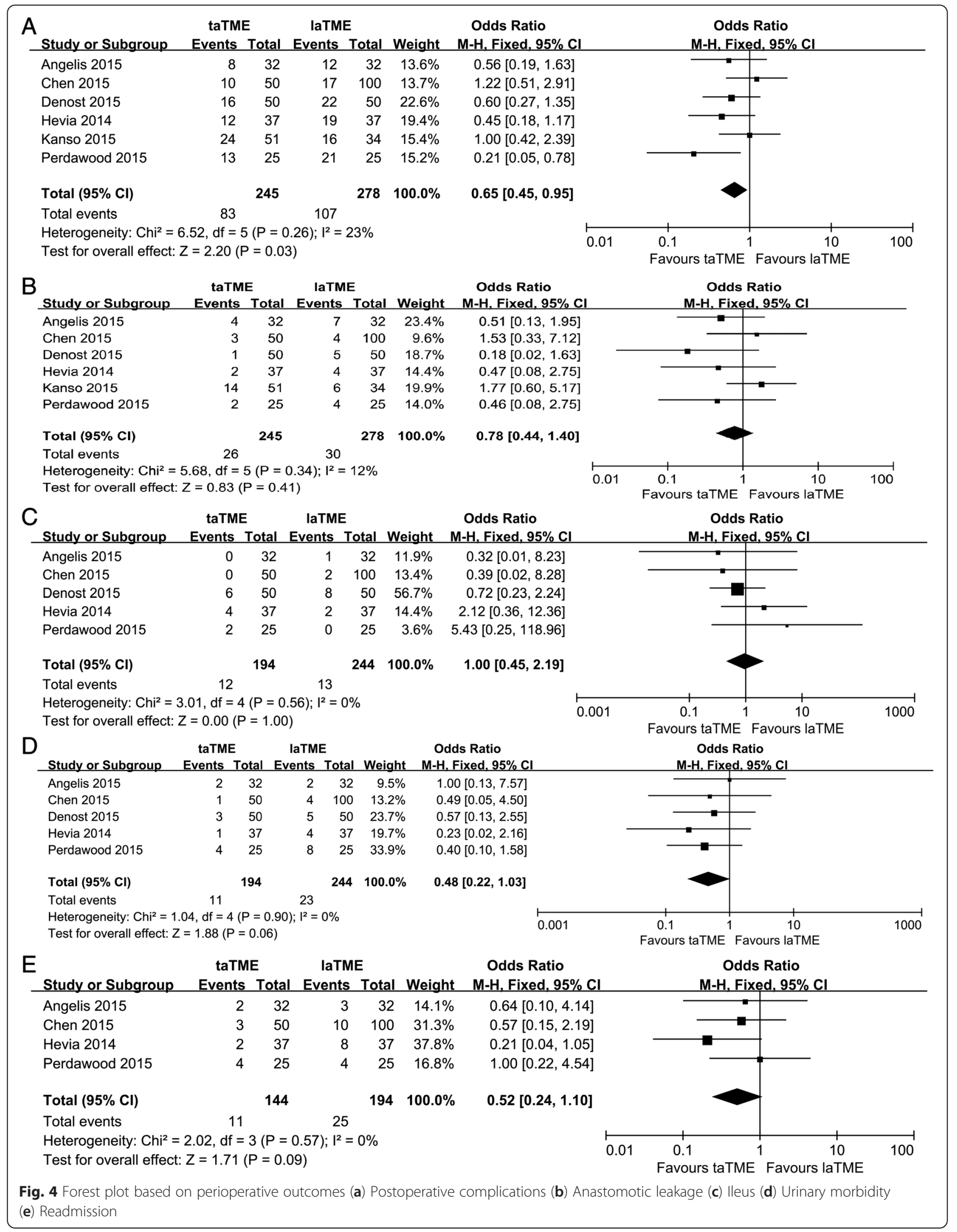


Table 3 Subgroup analysis based on total taTME

\begin{tabular}{|c|c|c|c|c|c|c|c|c|}
\hline \multirow[t]{2}{*}{ Outcomes } & \multicolumn{2}{|c|}{ No. of patients } & \multirow[t]{2}{*}{ No. of studies } & \multirow{2}{*}{$\begin{array}{l}\text { OR/WMD } \\
\text { Low high }\end{array}$} & \multirow[t]{2}{*}{$95 \% \mathrm{Cl}$} & \multicolumn{2}{|c|}{ Heterogeneity } & \multirow{2}{*}{$\begin{array}{l}P \\
\text { value }\end{array}$} \\
\hline & taTME & laTME & & & & $\overline{1^{2}}$ & $P$ value & \\
\hline \multicolumn{9}{|l|}{ Oncological outcomes } \\
\hline Mactoscopic quality of mesorectum & 119 & 119 & 4 & 2.03 & 0.994 .16 & $11 \%$ & 0.34 & 0.05 \\
\hline Harvested lymph nodes & 169 & 219 & 5 & -0.45 & -1.981 .08 & $0 \%$ & 0.93 & 0.56 \\
\hline Circumferential resection margin & 161 & 205 & 5 & 0.94 & 0.571 .30 & $20 \%$ & 0.29 & $<0.01^{*}$ \\
\hline Positive circumferential resectionmargin & 119 & 119 & 4 & 0.31 & 0.081 .18 & $0 \%$ & 0.90 & 0.09 \\
\hline Distal resection margin & 161 & 205 & 5 & 5.48 & -0.1711 .13 & $73 \%$ & $<0.01$ & 0.06 \\
\hline Positive distal resection margin & 83 & 66 & 2 & 5.98 & 0.7150 .5 & $0 \%$ & 0.92 & 0.10 \\
\hline \multicolumn{9}{|l|}{ Perioperative outcomes } \\
\hline Operative time & 144 & 194 & 4 & -23.29 & $-45.60-0.98$ & $72 \%$ & 0.01 & $0.04^{*}$ \\
\hline Conversion & 144 & 194 & 4 & 0.31 & 0.081 .18 & $0 \%$ & 0.90 & 0.09 \\
\hline Hospital stay & 144 & 194 & 4 & -1.62 & -3.620 .38 & $74 \%$ & 0.01 & 0.11 \\
\hline Intraoperative complications & 144 & 194 & 4 & 0.94 & 0.303 .01 & $0 \%$ & 0.60 & 0.92 \\
\hline Postoperative complications & 144 & 194 & 4 & 0.59 & 0.350 .97 & $45 \%$ & 0.14 & $0.04^{*}$ \\
\hline Anastomotic leakage & 144 & 194 & 4 & 0.65 & 0.301 .42 & $0 \%$ & 0.66 & 0.28 \\
\hline lleus & 144 & 194 & 4 & 1.37 & 0.454 .13 & $0 \%$ & 0.49 & 0.58 \\
\hline Acute urinary retention & 144 & 194 & 4 & 0.45 & 0.181 .10 & $0 \%$ & 0.81 & 0.08 \\
\hline Mobilization of splenic flexure & 112 & 162 & 3 & 2.34 & 0.995 .54 & $54 \%$ & 0.12 & 0.05 \\
\hline Readmission & 144 & 194 & 4 & 0.52 & 0.241 .10 & $0 \%$ & 0.57 & 0.09 \\
\hline
\end{tabular}

taTME transanal total mesorectal excision, IaTME laparoscopic total mesorectal excision, OR odds ratios, WMD weighted mean difference, $C I$ confidence interval; ${ }^{*} P$ vaule with statistical significance

to and open approach because of technical difficulty $(1 / 4 ; 25 \%)$, whereas eight patients in the laTME group $(8 / 17 ; 47 \%)$ underwent conversion. The significantly higher conversion rate in the laTME group was primarily due to the difficult pelvic approach in patients with unfavorable characteristics; taTME may overcome these limitations to decrease the incidence of conversion. Furthermore, our results showed a higher rate of moblization of splenic flexure in taTME group. Hence, we want to explore whether use of diverting ostomy may be an affecting factor for moblization of splenic flexure in our present study. Two included studies reported the data of using ostomy between two groups $[28,30]$. In study of Hevia et al [28], 86\% (32/37) patients in taTME group used diverting ileostomy and $81 \%(30 / 37)$ patients in laTME group $(P=0.53)$. In addition, Chen et al [30] indicated that 92\% (46/50) patients in taTME group underwent protective enterostomy in comparison with 91\% (91/100) patients in laTME group $(P=0.839)$. Based on this limited data, both groups showed equal rate of using ostomy and we could not get a definite correlation between undergoing ostomy and easier taking down splenic flexure in taTME group. Therefore, the potential factors affecting mobilization of splenic flexure in taTME cases needed to be further explored.

Safety is always the most important issue for a new technique. Our meta-analysis indicated a comparable rate of intraoperative complications and a significantly lower incidence of postoperative complications in the taTME group when compared with the laTME group. The tendency for a lower incidence of postoperative complications in the taTME group may also explain the lower readmission rate for these patients in comparison with the laTME group. However, these results need to be interpreted with caution because they are derived mainly from retrospective studies. Among the types of postoperative complication, our pooled analysis showed that the incidence of anastomotic leakage, ileus and urinary morbidity were comparable between the two groups. In fact, one of the included studies showed a higher incidence of anastomotic leakage in the taTME group [28]. The height of the anastomosis, a risk factor for the development of leakage, may explain this finding [47]. The distance of the tumor from the dentate line varied in the studies included, and was lower in the taTME group $(1.6 \mathrm{~cm}$ versus $1.8 \mathrm{~cm} ; P=0.11)$. Of note, an obviously lower incidence of urinary morbidity (infection, dysfunction and retention) was observed in the taTME group, although this did not reach statistical significance. A possible explanation is that taTME provides improved pelvic visualization with enhanced anatomical definition, allowing more accurate dissection through the presacral plane between the mesorectal and pelvic fascia, which may result in sparing of the autonomic nerves during 
mesorectal dissection, and therefore result in a lower incidence of urinary dysfunction [39, 42]. However, little is known about the long-term quality of life of these patients, or about the risk and the incidence of sexual and urinary dysfunction related to this procedure. Hence, the benefits of taTME with regard to postoperative complications need to be verified by multicenter RCTs.

As the new surgical technique of taTME is adopted increasingly by surgeons, the patient selection criteria will be crucial and will continue to animate debate. Based on the studies included in our meta-analysis, taTME was performed primarily in patients requiring surgical resection for mid- and low-rectal cancer. In addition, taTME may be more suitable for male patients with high BMI and a narrow pelvis. The study of Rouanet et al. [7] also confirmed that taTME is a feasible alternative surgical option to conventional laparoscopy for patients with unfavorable characteristics. Of note, the protocol published recently for a multicenter RCT comparing taTME with laTME (COLOR III) has formulated strict criteria for patient selection [25]. According to the selection criteria of this protocol, T3 tumors with margins $<1 \mathrm{~mm}$ to the endopelvic fascia, tumors with ingrowth in the internal sphincter or $\mathrm{m}$. levator ani and all $\mathrm{T} 4$ tumors as staged prior to neoadjuvant therapy were excluded [25]. However, the nature of the surgical candidates best suited to taTME treatment requires further study.

There were some limitations to our present metaanalysis. Except for one study (a RCT by Denost et al.) [32], the other studies included were all retrospective matched case-control trials, which slightly decreases the power of our meta-analysis. In addition, the results on both taTME and laTME were obtained at high volume centers with large minimally invasive proctectomy experiences. Hence, whether the comparable technical success of taTME could be achieved in low volume centers remained further study before this technique fully accepted by surgeon. Furthermore, a standardized procedure and transanal access platform of taTME were not formulated, and differences among the studies in surgical procedure and instruments may have contributed to the heterogeneity in our pooled analysis. Meanwhile, our study only indicated the benefits of taTME in short-term outcomes, compared with laTME; the long-term oncological and functional results should be awaited before completely adopting this new technique. Furthermore, the patients enrolled in our meta-analysis showed inconsistencies with regard to baseline information (age, BMI, neoadjuvant treatments, ASA, $\mathrm{pT}$ and $\mathrm{pN}$ stage). For example, the patients in the taTME group of the study by Perdawood et al. [26] showed a obviously higher BMI when compared with those in the laTME group $(P=0.07)$, the patients in the study of Hevia et al. [28] showed a difference in age between the two groups $(P=0.06)$, and the distance of tumor the above the anal verge showed a significant difference between groups in Chen's study $(P=0.02)$ [30]. Importantly, neoadjuvant treatments may be a potential confounding factor for the oncological outcomes of rectal cancer [48]. However, we could not conduct a subgroup analysis based on whether patients had received neoadjuvant treatments before surgical resection by all the possible means. Although the taTME group yielded longer distal margin lengths compared with laTME in the study of Chen et al. [30] (in which all the patients received neoadjuvant chemoradiation before surgery), studies stratified on the basis of neoadjuvant treatment are needed to verify the advantages of taTME.

\section{Conclusion}

Although some limitations existed in present study, our meta-analysis first provides that taTME can achieve comparable technical success in comparison with laTME, in the treatment of rectal cancer. Multicenter RCTs comparing taTME with laTME with longterm outcomes are required to evaluate the efficacy and safety of taTME further as a valid treatment for rectal cancer.

\begin{abstract}
Abbreviations
ASA, American Society of Anesthesiologists; BMI, body mass index; $\mathrm{Cl}_{\text {, }}$ confidence intervals; CRM, circumferential resection margin; DRM, distal resection margin; laTME, laparoscopic total mesorectal excision; NOS, Newcastle-Ottawa Scale; NOTES, natural orifice transluminal endoscopic surgery; ORs, odds ratios; RCTs, randomized clinical trials; SD, standard deviation; TAMIS, transanal minimally invasive surgery; TATA, transabdominal-transanal; taTME, transanal total mesorectal excision; TME, total mesorectal excision; WMD, weighted mean difference
\end{abstract}

\section{Acknowledgments}

We thank the Department of Surgical Oncology of First Hospital of China Medical University and the College of China Medical University for technical assistance.

\section{Funding}

This work was funded by Natural Science Foundation of Liaoning Province (No. 2014029201), Program of Education Department of Liaoning Province (L2014307), the Key Laboratory Programme of Education Department of Liaoning Province (LZ2015076).

\section{Availability of data and materials}

As this is a systematic review and meta-analysis, all eligible studies in our paper are listed in the reference and manuscript.

\section{Authors' contributions}

BM, PG and ZNW were responsible for conception and design of the study. $B M$ and PG did the studies selection, data extraction, statistical analyses and wrote the paper. CZ reviewed and checked all the final data. CZ, CWZ and LYW participated in studies selection and data extraction and provided statistical expertise. HPL contributed to the literature search, studies selection and figures. YSS and ZNW provided clinical expertise and interpretation of data. The paper was drafted, revised and approved by all investigators. All authors read and approved the final manuscript.

\section{Authors' information}

Zhenning Wang: Professor and Director of Department of Surgical Oncology, First Hospital of China Medical University; Chief of Department of Strategic Planning and Academic Discipline Construction, China Medical University; 
Chang Jiang Scholars of the Ministry of Education; Vice Chairman of Professional Committee of Colorectal Cancer, Anti-cancer Association of Liaoning Province; Vice Chairman of Youth Committee of Oncology, Chinese Medical Association.

\section{Competing interests}

The authors declare that they have no competing interests.

\section{Consent for publication}

Not applicable.

\section{Ethics approval and consent to participate}

Not applicable.

Received: 9 February 2016 Accepted: 27 June 2016

Published online: 04 July 2016

\section{References}

1. Siegel RL, Miller KD, Jemal A. Cancer statistics. 2015. CA Cancer J Clin. 2015;65(1):5-29.

2. Heald RJ, Husband EM, Ryall RD. The mesorectum in rectal cancer surgery-the clue to pelvic recurrence? Br J Surg. 1982;69(10):613-6.

3. Bonjer HJ, Deijen $\mathrm{CL}$, Abis GA, Cuesta MA, van der Pas MH, de Lange-de Klerk ES, et al. A randomized trial of laparoscopic versus open surgery for rectal cancer. N Engl J Med. 2015;372(14):1324-32.

4. Jeong SY, Park JW, Nam BH, Kim S, Kang SB, Lim SB, et al. Open versus laparoscopic surgery for mid-rectal or low-rectal cancer after neoadjuvant chemoradiotherapy (COREAN trial): survival outcomes of an open-label, non-inferiority, randomised controlled trial. Lancet Oncol. 2014;15(7):767-74.

5. Kang SB, Park JW, Jeong SY, Nam BH, Choi HS, Kim DW, et al. Open versus laparoscopic surgery for mid or low rectal cancer after neoadjuvant chemoradiotherapy (COREAN trial): short-term outcomes of an open-label randomised controlled trial. Lancet Oncol. 2010;11(7):637-45.

6. Jayne DG, Thorpe HC, Copeland J, Quirke P, Brown JM, Guillou PJ. Five-year follow-up of the Medical Research Council CLASICC trial of laparoscopically assisted versus open surgery for colorectal cancer. Br J Surg. 2010;97(11):1638-45

7. Rouanet P, Mourregot A, Azar CC, Carrere S, Gutowski M, Quenet F, et al. Transanal endoscopic proctectomy: an innovative procedure for difficult resection of rectal tumors in men with narrow pelvis. Dis Colon Rectum 2013;56(4):408-15.

8. Penninckx F, Kartheuser A, Van de Stadt J, Pattyn P, Mansvelt B, Bertrand C, et al. Outcome following laparoscopic and open total mesorectal excision for rectal cancer. Br J Surg. 2013;100(10):1368-75.

9. Lujan J, Valero G, Hernandez Q, Sanchez A, Frutos MD, Parrilla P. Randomized clinical trial comparing laparoscopic and open surgery in patients with rectal cancer. Br J Surg. 2009;96(9):982-9.

10. Marks JH, Frenkel JL, D'Andrea AP, Greenleaf CE. Maximizing rectal cancer results: TEM and TATA techniques to expand sphincter preservation. Surg Oncol Clin N Am. 2011;20(3):501-20.

11. Atallah SB, Larach S, deBeche-Adams TC, Albert MR. Transanal minimally invasive surgery (TAMIS): a technique that can be used for retrograde proctectomy. Dis Colon Rectum. 2013;56(7):931.

12. de Lacy AM, Rattner DW, Adelsdorfer C, Tasende MM, Fernandez M, Delgado S, et al. Transanal natural orifice transluminal endoscopic surgery (NOTES) rectal resection: "down-to-up" total mesorectal excision (TME)-short-term outcomes in the first 20 cases. Surg Endosc. 2013;27(9):3165-72.

13. Sylla P, Rattner DW, Delgado S, Lacy AM. NOTES transanal rectal cancer resection using transanal endoscopic microsurgery and laparoscopic assistance. Surg Endosc. 2010;24(5):1205-10.

14. Lacy AM, Tasende MM, Delgado S, Fernandez-Hevia M, Jimenez M, De Lacy B, et al. Transanal Total Mesorectal Excision for Rectal Cancer: Outcomes after 140 Patients. J Am Coll Surg. 2015;221(2):415-23.

15. Veltcamp Helbach M, Deijen CL, Velthuis S, Bonjer HJ, Tuynman JB, Sietses $C$. Transanal total mesorectal excision for rectal carcinoma: short-term outcomes and experience after 80 cases. Surg Endosc. 2016:30(2):464-70

16. Muratore A, Mellano A, Marsanic P, De Simone M. Transanal total mesorectal excision (taTME) for cancer located in the lower rectum: short- and mid-term results. Eur J Surg Oncol. 2015;41(4):478-83.
17. Panic N, Leoncini E, de Belvis G, Ricciardi W, Boccia S. Evaluation of the endorsement of the preferred reporting items for systematic reviews and meta-analysis (PRISMA) statement on the quality of published systematic review and meta-analyses. PLoS ONE. 2013;8(12):e83138.

18. Stang A. Critical evaluation of the Newcastle-Ottawa scale for the assessment of the quality of nonrandomized studies in meta-analyses. Eur J Epidemiol. 2010;25(9):603-5.

19. Hozo SP, Djulbegovic B, Hozo I. Estimating the mean and variance from the median, range, and the size of a sample. BMC Med Res Methodol. 2005;5:13.

20. Higgins JP, Thompson SG, Deeks JJ, Altman DG. Measuring inconsistency in meta-analyses. BMJ. 2003;327(7414):557-60.

21. Petitti DB. Approaches to heterogeneity in meta-analysis. Stat Med. 2001;20(23):3625-33.

22. Lacy AM, Espin E, Biondo S, Fernández-Hevia M, Tasende M, Jimenez M, et al. Transanal total mesorectal excision versus laparoscopic total mesorectal excision. Randomized study comparing 30-day postoperative morbidity. Color Dis. 2014;16:106.

23. Lelong B, Mege D, Meillat H, Fara R, Delpero JR, De Chaisemartin C. Endoscopic transanal or laparoscopic transabdominal mesorectal excision for low rectal cancer: A single institutional case control study. Color Dis. 2014;16:8.

24. Marks JH, Montenegro GA, Shields M, Marks G. Evolution of colorectal notes surgery: Bottoms up transabdominal transanal (TATA)/total mesorectal excision (TME): A case matched study of transanal TME surgery for rectal cancer. J Am Coll Surg. 2014;219(4):e72.

25. Deijen CL, Velthuis S, Tsai A, Mavroveli S, de Lange-de Klerk ES, Sietses C, et al. COLOR III: a multicentre randomised clinical trial comparing transanal TME versus laparoscopic TME for mid and low rectal cancer. Surg Endosc. 2015. doi:10.1007/s00464-015-4615-X.

26. Perdawood SK, Al Khefagie GA. Transanal versus laparoscopic total mesorectal excision for rectal cancer: Initial experience from Denmark. Colorectal Dis. 2016;18(1):51-8.

27. Kanso F, Maggiori L, Debove C, Chau A, Ferron M, Panis Y. Perineal or Abdominal Approach First During Intersphincteric Resection for Low Rectal Cancer: Which Is the Best Strategy? Dis Colon Rectum. 2015;58(7):637-44.

28. Fernandez-Hevia M, Delgado S, Castells A, Tasende M, Momblan D. Diaz del Gobbo G, et al. Transanal total mesorectal excision in rectal cancer: short-term outcomes in comparison with laparoscopic surgery. Ann Surg. 2015;261(2):221-7

29. de'Angelis N, Portigliotti L, Azoulay D, Brunetti F. Transanal total mesorectal excision for rectal cancer: a single center experience and systematic review of the literature. Langenbecks Arch Surg. 2015; doi:10.1007/s00423-015-1350-7.

30. Chen CC, Lai YL, Jiang JK, Chu CH, Huang IP, Chen WS, et al. Transanal Total Mesorectal Excision Versus Laparoscopic Surgery for Rectal Cancer Receiving Neoadjuvant Chemoradiation: A Matched Case-Control Study. Ann Surg Oncol. 2015. doi:10.1245/s10434-015-4997-y.

31. Velthuis S, Nieuwenhuis DH, Ruijter TE, Cuesta MA, Bonjer HJ, Sietses C. Transanal versus traditional laparoscopic total mesorectal excision for rectal carcinoma. Surg Endosc. 2014;28(12):3494-9.

32. Denost Q, Adam JP, Rullier A, Buscail E, Laurent C, Rullier E. Perineal transanal approach: a new standard for laparoscopic sphincter-saving resection in low rectal cancer, a randomized trial. Ann Surg. 2014;260(6):993-9.

33. Quirke P, Durdey P, Dixon MF, Williams NS. Local recurrence of rectal adenocarcinoma due to inadequate surgical resection. Histopathological study of lateral tumour spread and surgical excision. Lancet. 1986;2(8514):996-9.

34. Rullier E. Transanal Mesorectal Excision: The New Challenge in Rectal Cancer. Dis Colon Rectum. 2015;58(7):621-2.

35. Stevenson AR, Solomon MJ, Lumley JW, Hewett P, Clouston AD, Gebski VJ, et al. Effect of Laparoscopic-Assisted Resection vs Open Resection on Pathological Outcomes in Rectal Cancer: The ALaCaRT Randomized Clinical Trial. JAMA. 2015;314(13):1356-63.

36. Fleshman J, Branda M, Sargent DJ, Boller AM, George V, Abbas M, et al. Effect of Laparoscopic-Assisted Resection vs Open Resection of Stage II or III Rectal Cancer on Pathologic Outcomes: The ACOSOG Z6051 Randomized Clinical Trial. JAMA. 2015:314(13):1346-55.

37. Serra-Aracil X, Mora-Lopez L, Alcantara-Moral M, Caro-Tarrago A, Gomez-Diaz CJ, Navarro-Soto S. Transanal endoscopic surgery in rectal cancer. World J Gastroenterol. 2014;20(33):11538-45.

38. Keller DS, Haas EM. Transanal Minimally Invasive Surgery: State of the Art. J Gastrointest Surg. 2016;20(2):463-9. 
39. Wolthuis AM, de Buck van Overstraeten A, D'Hoore A. Laparoscopic natural orifice specimen extraction-colectomy: a systematic review. World J Gastroenterol. 2014;20(36):12981-92.

40. Simillis C, Hompes R, Penna M, Rasheed S, Tekkis PP. A systematic review of transanal total mesorectal excision. Is this the future of rectal cancer surgery? Colorectal Dis. 2016;18(1):19-36.

41. Buchs NC, Nicholson GA, Ris F, Mortensen NJ, Hompes R. Transanal total mesorectal excision: A valid option for rectal cancer? World J Gastroenterol. 2015;21(41):11700-8.

42. Motson RW, Lacy A. The Rationale for Transanal Total Mesorectal Excision. Dis Colon Rectum. 2015;58(9):911-3.

43. Heald RJ. A new solution to some old problems: transanal TME. Tech Coloproctol. 2013;17(3):257-8.

44. Nagtegaal ID, van de Velde CJ, van der Worp E, Kapiteijn E, Quirke P, van Krieken JH, et al. Macroscopic evaluation of rectal cancer resection specimen: clinical significance of the pathologist in quality control. J Clin Oncol. 2002;20(7):1729-34.

45. Nagtegaal ID, Quirke P. What is the role for the circumferential margin in the modern treatment of rectal cancer? J Clin Oncol. 2008;26(2):303-12.

46. Nagtegaal ID, Marijnen CA, Kranenbarg EK, van de Velde CJ, van Krieken JH. Pathology Review Committee, et al. Circumferential margin involvement is still an important predictor of local recurrence in rectal carcinoma: not one millimeter but two millimeters is the limit. Am J Surg Pathol. 2002;26(3):350-7.

47. Tortorelli AP, Alfieri S, Sanchez AM, Rosa F, Papa V, Di Miceli D, et al. Anastomotic leakage after anterior resection for rectal cancer with mesorectal excision: incidence, risk factors, and management. Am Surg. 2015;81(1):41-7.

48. Hav M, Libbrecht L, Ferdinande L, Geboes K, Pattyn P, Cuvelier CA. Pathologic Assessment of Rectal Carcinoma after Neoadjuvant Radio(chemo)therapy: Prognostic Implications. BioMed Res Int. 2015;2015:574540.

\section{Submit your next manuscript to BioMed Central and we will help you at every step:}

- We accept pre-submission inquiries

- Our selector tool helps you to find the most relevant journal

- We provide round the clock customer support

- Convenient online submission

- Thorough peer review

- Inclusion in PubMed and all major indexing services

- Maximum visibility for your research

Submit your manuscript at www.biomedcentral.com/submit 